\title{
Cardiovascular risk and white matter lesions after endocrine control of Cushing's syndrome
}

\author{
Alicia Santos ${ }^{1}$, Eugenia Resmini ${ }^{1}$, Beatriz Gómez-Ansón ${ }^{2}$, Iris Crespo', \\ Esther Granell ${ }^{2}$, Elena Valassi ${ }^{1}$, Patricia Pires $^{3}$, Yolanda Vives-Gilabert ${ }^{3}$, \\ M Antonia Martínez-Momblán ${ }^{1,4}$, Manuel de Juan², Maria Mataró ${ }^{5}$ \\ and Susan $\mathbf{M}$ Webb'
}

\begin{abstract}
${ }^{1}$ Endocrinology/Medicine Departments, Hospital Sant Pau, Centro de Investigación Biomédica en Red de Enfermedades Raras (CIBERER, Unidad 747), IIB-Sant Pau, ISCIII and Universitat Autònoma de Barcelona (UAB), Sant Antoni Maria Claret n. 167, 08025 Barcelona, Spain, ${ }^{2}$ Neuroradiology Unit, Hospital de Sant Pau, and IIB-Sant Pau, UAB, Barcelona, Spain, ${ }^{3}$ INNDACYT, Avda. Europa, 20, planta baja puerta D 08907, Hospitalet de Llobregat, Spain, ${ }^{4}$ Escola Universitària d'Infermeria, Hospital de Sant Pau. Universitat Autònoma de Barcelona (UAB), Barcelona, Spain and ${ }^{5}$ Department of Psychiatry and Clinical Psychobiology, Psychology Faculty, Institute for Brain, Cognition and Behaviour (IR3C), Universitat de Barcelona (UB), Barcelona, Spain
\end{abstract}

Correspondence should be addressed to A Santos

Email

asantos@santpau.cat

\section{Abstract}

Objective: Cushing's syndrome (CS) is associated with high cardiovascular risk. White matter lesions (WML) are common on brain magnetic resonance imaging (MRI) in patients with increased cardiovascular risk.

Aim: To investigate the relationship between cardiovascular risk, WML, neuropsychological performance and brain volume in CS.

Design/methods: Thirty-eight patients with CS (23 in remission, 15 active) and 38 controls sex-, age- and education-level matched underwent a neuropsychological and clinical evaluation, blood and urine tests and 3Tesla brain MRI. WML were analysed with the Scheltens scale. Ten-year cardiovascular risk (10CVR) and vascular age (VA) were calculated according to an algorithm based on the Framingham heart study.

Results: Patients in remission had a higher degree of WML than controls and active patients $(P<0.001$ and $P=0.008$ respectively), which did not correlate with cognitive performance in any group. WML severity positively correlated with diastolic blood pressure $(r=0.659, P=0.001)$ and duration of hypertension $(r=0.478, P=0.021)$ in patients in remission. Both patient groups (active and in remission) had higher 10CVR $(P=0.030, P=0.041)$ and VA than controls $(P=0.013, P=0.039)$. Neither the 10CVR nor the VA correlated with WML, although both negatively correlated with cognitive function and brain volume in patients in remission $(P<0.05)$. Total brain volume and grey matter volume in both CS patient groups were reduced compared to controls (total volume: active $P=0.006$, in remission $P=0.012$; grey matter: active $P=0.001$, in remission $P=0.003)$, with no differences in white matter volume between groups.

Conclusions: Patients in remission of Cushing's syndrome (but not active patients) have more severe white matter lesions than controls, positively correlated with diastolic pressure and duration of hypertension. Ten-year cardiovascular risk and vascular age appear to be negatively correlated with the cognitive function and brain volume in patients in remission of Cushing's syndrome.

\section{Introduction}

Cushing's syndrome (CS) is a rare disease due to a chronic glucocorticoid excess. When endogenous, the most common cause is a pituitary adenoma and, less frequently, an adrenal or ectopic tumour (1). CS is associated with severe morbidities and increased mortality, due to systemic complications, that may persist after cure. (c) 2015 European Society of Endocrinology Printed in Great Britain
Published by Bioscientifica Ltd. 
These include central obesity, increased fat mass, reduced bone and lean body mass, excessive fatigue, skin lesions (purple striae, easy bruising, ulceration), hirsutism, hypogonadism, hypertension, insulin resistance and/or diabetes mellitus, dyslipidemia, prothrombotic state, vascular disease, atherosclerosis, depression, anxiety, cognitive decline and impaired health-related quality of life $(1,2$, $3,4,5,6$ ). Available treatments include surgery (pituitary adenomectomy, adrenalectomy or excision of the ectopic source of the adrenocorticotrophic hormone (ACTH)), irradiation and cortisol-lowering drugs $(7,8)$.

Glucocorticoids can be neurotoxic to the brain by modifying both neuronal structure and neurotransmission (3). This can impair adult neurogenesis, lead to region-specific alterations in dendrite and spine morphology (i.e., reducing dendritic length and branching morphology), impair hippocampal long-term potentiation and synaptic plasticity and also imply inappropriate functional responses after a brief stress exposure $(9,10)$. Reduced brain volume, both general and specifically in the cerebellum or the hippocampus, has been described in CS $(11,12,13,14,15)$. Patients also present neuropsychological alterations, mainly involving memory. Moreover impairment in executive functions, attention, visuoconstructive functions, language, information processing speed and motor functions are also present in these patients, although less consistently (10, $11,13,14,16,17)$. Because some brain and neuropsychological alterations are still present after biochemical cure, it is suggested that the consequences of cortisol excess on the brain are not completely reversible $(3,18,19)$.

It is well known that suffering or having suffered CS determines a higher cardiovascular risk $(20,21)$. Cardiovascular risk has consistently been linked to cognitive impairments and brain white matter lesions (WML) (22). WML (also known as leukoaraiosis) are evidenced on brain MRI as hyperintensities on T2 or FLAIR images and usually correspond to myelin loss and mild gliosis in brain areas (23). In both aging and dementia, immunohistochemistry on WML has revealed activated microglia, clasmatodendritic astrocytosis, oligodendroglia apoptosis and upregulated markers of hypoxia (24). They are supposed to have an ischemic origin, due to the obstruction of small cerebral vessels, which lead to acute or chronic ischaemia (25). These WML are a common finding in patients with high cardiovascular risk, like in hypertension, hypercholesterolemia or diabetes, although they are also common in the elderly, increasing with age (26). WML have important clinical implications, as they have been related to poor cognition, mainly in tests associated to executive functioning but also with information processing speed, memory, attention and psychomotor speed $(23,25)$. Furthermore, they have also been related to an increased risk of dementia, stroke and death (22). These lesions are not static and may worsen over time, increasing in number and volume. Baseline severity is perhaps the most consistent predictor of progression, although other reported factors are female sex and high blood pressure. WML progression has also been associated with cognitive decline $(25,27)$.

Patients with CS have increased cardiovascular risk and therefore may be prone to develop WML. Reduced integrity of brain white matter has been reported in CS, indicating axon impairment $(28,29)$. This has been established using diffusion tension imaging, a noninvasive neuroimaging technique that assesses the motion of water molecules along and across neuronal axons (28). A specific software is needed to perform this kind of analysis. In contrast, WML are characterized by macroscopic lesions, which can be seen and evaluated directly on MRI by physicians in their clinical practice. Therefore, the aim of this study was to investigate the relationship between cardiovascular risk and WML, neuropsychological performance and brain volume in CS. Our hypothesis was that cardiovascular risk would have a role on WML and that patients with CS (both active and in remission) would have more WML than controls. Furthermore, both cardiovascular risk and WML would be related to cognitive deficits and decreased brain volume.

\section{Subjects and methods}

\section{Patients}

The study included 38 patients with CS (23 in remission, 15 active) routinely followed in our hospital and 38 controls matched for sex, age and years of education ( \pm 3 years). Initially, 59 patients were approached; five were not right-handed and were excluded. From the 54 remaining patients, five declined to participate (citing lack of time or interest), nine had claustrophobia and could not undergo an MRI and two had medical incompatibilities for the MRI. Controls were recruited from the blood donor's center of the hospital and also from other current studies. A matched control was identified and recruited for each patient. Initially, 63 controls were invited to participate in the study; seven were not right-handed and were excluded. From the remaining controls, eight declined to participate (citing lack of time or interest), nine were excluded as they could 
not undergo an MRI due to claustrophobia and one was excluded due to exogenous chronic glucocorticoid exposure. The study was approved by the hospital's ethics committee, and all patients and controls signed an informed consent before they were enrolled in the study.

Exclusion criteria for patients with CS were age above 65 years, growth hormone (GH) deficiency, known prior cerebrovascular disease, severe neurological or psychiatric illness and history of drug or alcohol abuse. For controls, endocrine disease and glucocorticoid exposure were additional exclusion criteria. Only right-handed patients with CS and controls were included (Edinburgh Handedness Inventory $>80)(30)$.

Patients were considered biochemically cured of CS after surgery if adrenal insufficiency was demonstrated or if morning cortisol suppression $(<50 \mathrm{nmol} / \mathrm{l})$ was observed after $1 \mathrm{mg}$ dexamethasone overnight (16) and if repeated 24-h urinary-free cortisol measures were normal $(<280 \mathrm{nmol} / \mathrm{l})$. Patients who did not fulfil these criteria were considered to have active CS.

\section{Clinical interview, neuropsychological assessment and biochemistry}

Both patients and controls underwent a complete clinical interview, which included demographic data, clinical history, family history, any current treatments and an assessment of blood pressure, height, weight and waist circumference. The clinical interview for patients with CS also included details on disease history, with a review of clinical files.

Patients and controls also underwent a neuropsychological battery of tests. Tests evaluating functions that have been related to WML in the literature $(23,25)$ were selected, including Memory: Rey-Osterrieth Complex Figure (31) and Rey Auditory Verbal-Learning Test (32); Attention: Digit Span Forward (33) and Continuous Performance Test II (34); Executive function: Trail Making Test B (35), FAS (36), Animals (37), Wisconsin Card Sorting Test (38) and Digit Span Backwards (33); Information processing speed: Symbol Digit Modalities Test (39), Wisconsin Card Sorting Test (mean time) (38) and Continuous Performance Test - II (hit reaction time); Motor functions: Grooved Pegboard (40) and Trail Making Test A (35). A further description of the tests can be found in Supplementary Table 1, see section on supplementary data given at the end of this article. Individual test scores were converted into Z-scores. In addition, Z-scores where higher scores were related to a poorer performance were inverted to guarantee that all scores were equivalent.
A Z-score of each cognitive domain was calculated, as the mean of all Z-scores of the tests selected for a particular cognitive function. Specifically, the cognitive domains included the following scores: Memory: Rey-Osterrieth Complex Figure (immediate and delayed recall) and Rey Auditory Verbal-Learning Test (Rey 5 and Recognition A); Attention: Digit Span Forward (total score) and Continuous Performance Test II (omissions); Executive function: Trail Making Test B (total time), FAS (total score), Animals (total score), Wisconsin Card Sorting Test (perseverative errors) and Digit Span Backwards (total score); Information processing speed: Symbol Digit Modalities Test (total score), Wisconsin Card Sorting Test (mean time) and Continuous Performance Test II (hit reaction time); Motor functions: Grooved Pegboard (total time for both dominant and non-dominant hand) and Trail Making Test A (total time) $(41,42)$.

Two questionnaires to assess depression (Beck Depression Inventory II (BDI-II)) and anxiety (State Trait Anxiety Inventory (STAI), which assesses both state and trait anxiety) were also included in the study protocol. To rule out an intra-examiner effect, all assessments were performed by one neuropsychologist (A Santos).

Participants also had blood and urine tests. Urinary free cortisol was determined from a 24 -h collection using a commercial radioimmunoassay. To assess cholesterol, triglycerides and glucose from blood samples, standard assay determinations were performed.

\section{Magnetic resonance imaging}

All participants underwent 3-Tesla magnetic resonance imaging (MRI) of the whole brain. MRI was obtained using a 3-Tesla Philips Achieva facility (Software version 2.1.3.2) and a dedicated acquisition protocol: 3DMPRAGE whole brain sequence (repetition time $=6.7 \mathrm{~ms}$; echo time $=$ $3.1 \mathrm{~ms}, 170$ slices; voxel size $=1 \times 1 \times 1.2$; field of view $=$ $256 \times 256 \times 204$ ) and FLAIR (repetition time $=8000 \mathrm{~ms}$; echo time $=332 \mathrm{~ms}$; voxel size $=1.1 \times 1.1 \times 0.6$; field of view $=250 \times 250 \times 250$ ). The complete acquisition protocol lasted approximately $45 \mathrm{~min}$. FLAIR images were analysed by two blinded neuroradiologists, who scored the degree of WML according to the semiquantitative rating scale described by Scheltens (Scheltens scale) (43).

The Scheltens scale can range from 0 to 84 in which a higher score indicates a higher degree of WML. The score is the sum of four subscores rated in a semiquantitave way. It includes white matter hyperintensities in the periventricular area (score: 0-6), the cerebral lobes (score: 0-24), the basal ganglia (score 0-30) and the infratentorial area 
(score 0-30). Scores depend on both the presence of lesions in different areas and the size of the lesion.

Furthermore, the routine MRI reports prepared by the radiologists before using the Scheltens scale were collected from the clinical files of patients and controls to analyse in how many the presence of WML had already been registered. This information was categorized in a dichotomic way (detecting WML: yes/no).

Additionally, structural T1 MRIs were processed at the Port d'Informació Científica (PIC) of the Universitat Autonoma de Barcelona. Whole brain, grey matter and white matter volumes were measured using FreeSurfer v5.3 Software (http://surfer.nmr.mgh.harvard.edu/). These volumes were normalised to the estimated intracranial volume (eTIV) of each individual, as previously described (14).

\section{Cardiovascular risk evaluation}

Ten-year cardiovascular risk and vascular age were calculated with a sex-specific multivariable risk factor algorithm, which includes sex, age, systolic blood pressure, smoking, diabetes, HDL and total cholesterol, based on the Framingham heart study data (44). This algorithm was developed using the longitudinal data of 8491 patients. The algorithm provides two scores: a percent risk of suffering a cardiovascular event over the next 10 years (10-year cardiovascular risk) and a further quantification of this risk in the form of vascular age/heart age (vascular age).

\section{Statistical analysis}

Statistical analysis was performed using IBM SPSS 21 software (SPSS, Inc.). Normal distribution was analysed using the Kolmogorov-Smirnov test. ANOVA followed by a post hoc analysis using Bonferroni was used for comparisons between the three groups (controls, active patients and patients in remission). For non-normal data (10-year cardiovascular risk, Scheltens score, Beck depression score and triglyceride level), the Kruskal-Wallis test was used, and the post hoc analysis was performed with a Mann Whitney $U$ test. Student's $t$-test or Mann Whitney $U$ test for non-parametric variables were used when comparing two groups. $\chi^{2}$ was used to compare categorical variables. Correlations were assessed using the Pearson coefficient or the Sperman's $\rho$ for non-parametric variables. Differences were considered significant when $P<0.05$.

\section{Results}

Demographic and clinical characteristics of patients and controls are shown in Table 1 . There were no differences between groups for age, sex and educational level, as expected due to prior matching.

\section{Cardiovascular risk}

The first analysis was devoted to cardiovascular risk. Regarding the 10-year cardiovascular risk, both CS patient groups (active and in remission) had a higher risk of suffering a cardiovascular event during the next 10 years

Table 1 Clinical and demographic characteristics of patients (CS, active and in remission) and controls.

\begin{tabular}{|c|c|c|c|}
\hline & \multicolumn{2}{|c|}{ CS } & \multirow[b]{2}{*}{ Controls $(n=38)$} \\
\hline & Active $(n=15)$ & In remission $(n=23)$ & \\
\hline Age & $44.3 \pm 9.3$ & $42.9 \pm 10.6$ & $42.7 \pm 10.3$ \\
\hline Sex (female/male) & $13 / 2$ & $19 / 4$ & $32 / 6$ \\
\hline Years of education & $13.7 \pm 2.7$ & $13.2 \pm 3.3$ & $13.7 \pm 3.3$ \\
\hline Origin of CS (pituitary/adrenal/ectopic/AIMAH ${ }^{\dagger}$ ) & $10 / 3 / 1 / 1$ & $20 / 3 / 0 / 0$ & - \\
\hline Surgery (transsphenoidal/adrenal) & $1 / 0$ & $20 / 3$ & - \\
\hline Radiotherapy & - & 5 & - \\
\hline $\begin{array}{l}\text { Cortisol lowering medication (metyrapone/ketokonazole/ } \\
\text { cabergoline/losartan) }\end{array}$ & $4 / 7 / 1 / 1$ & - & - \\
\hline Hydrocortisone replacement & - & 8 & - \\
\hline Waist circumference (cm) & $98.0 \pm 11.7 *$ & $93.1 \pm 14.8 *$ & $82.2 \pm 11.3$ \\
\hline Total cholesterol (mmol/l) & $5.2 \pm 0.7$ & $5.2 \pm 1.0$ & $5.1 \pm 0.9$ \\
\hline Triglycerides (mmol/l) & $1.0(0.6-2.2) *$ & $1.2(0.6-3.9) *$ & $0.7(0.5-2.4)$ \\
\hline Systolic blood pressure $(\mathrm{mm} / \mathrm{Hg})$ & $132.0 \pm 21.7 *$ & $131.2 \pm 21.3 *$ & $112.8 \pm 15.9$ \\
\hline Diastolic blood pressure $(\mathrm{mm} / \mathrm{Hg})$ & $84.0 \pm 15.6 *$ & $82.3 \pm 10.7 *$ & $69.9 \pm 11.2$ \\
\hline Glucose (mmol/l) & $4.9 \pm 0.54$ & $4.9 \pm 0.51$ & $4.8 \pm 0.54$ \\
\hline
\end{tabular}

*Significant differences between patients and controls $(P<0.05)$. All values are expressed as mean \pm s.D., except for triglycerides, expressed as median and range.

${ }^{\dagger} \mathrm{ACTH}$-independent macronodular adrenal hyperplasia. 
Table 2 Scheltens scale scores in patients (CS, active and in remission) and normal controls. The number of patients and controls who showed each score is indicated.

\begin{tabular}{|c|c|c|c|c|c|c|c|c|c|c|c|c|c|c|c|c|c|}
\hline & \multicolumn{17}{|c|}{ Scheltens scale scores ${ }^{a}$} \\
\hline & $0 *$ & 1 & 2 & 3 & 4 & 5 & 6 & 7 & 8 & 9 & 10 & 11 & 12 & 13 & 14 & $>15$ & $\begin{array}{l}\text { Median } \\
\text { and range }\end{array}$ \\
\hline $\begin{array}{r}\text { Active CS } \\
(n=15)\end{array}$ & 5 & 4 & 2 & 2 & 1 & 0 & 0 & 0 & 1 & 0 & 0 & 0 & 0 & 0 & 0 & 0 & $1 ; 0-8$ \\
\hline $\begin{array}{l}\text { In remission CS } \\
\quad(n=23)\end{array}$ & 4 & 4 & 1 & 3 & 1 & 1 & 2 & 1 & 1 & 3 & 0 & 0 & 0 & 1 & 1 & 0 & $3 ; 0-14$ \\
\hline $\begin{array}{l}\text { Controls } \\
\quad(n=38)\end{array}$ & 17 & 10 & 4 & 2 & 2 & 2 & 1 & 0 & 0 & 0 & 0 & 0 & 0 & 0 & 0 & 0 & $1 ; 0-6$ \\
\hline
\end{tabular}

than controls $(P=0.037$ and $P=0.044$ respectively). More specifically, active patients had a $8.1 \%$ risk, followed by patients in remission (7.4\% risk) and controls (3.9\% risk).

Regarding vascular age, both patient groups had a higher vascular age than controls $(56.1 \pm 16.8$ years in active patients with CS, $P=0.013 ; 52.5 \pm 19.8$ years in patients in remission, $P=0.039$; vs $42.1 \pm 11.9$ years in controls). This was remarkable, as the sample was initially matched for age (mean between 42.7 and 44.3 years). In fact, both patient groups (but not controls) had an increased mean vascular age compared to their current age (active CS 11.8 years more, $P=0.005$; CS in remission 9.6 years more, $P=0.002$ ).

Regarding specific parameters associated with cardiovascular risk, patients with CS (both in remission and active) had a greater waist circumference $(P=0.005$, $P<0.001)$, triglyceride level $(P=0.001, P=0.002)$, diastolic blood pressure $(P=0.001, P<0.001)$ and systolic blood pressure $(P=0.001, P=0.004)$ than controls (Table 1$)$. No differences were found for glucose level, cholesterol level or smoking habits between groups. Patients in remission had a longer hypertension duration (measured in months since diagnosis) than active patients $(P=0.048)$.

No differences were found for 10-year cardiovascular risk or vascular age when comparing patients of pituitary or adrenal origin, either active or in remission.

\section{White matter lesions}

A second analysis was devoted to WML, which mainly presented as small periventricular foci in patients and controls. Patients with CS in remission had a higher degree of WML than controls and active CS, measured with the Scheltens scale $(P=0.001$ and $P=0.035$ respectively) (Table 2 and Fig. 1). Active patients did not differ in
WML compared to controls. There were also significant differences in the number of patients whose routine MRI report described the presence of WML (in remission $73.9 \%$, active $46.7 \%$, controls $28.9 \%$; $P=0.001$ ).

No differences were found in the Scheltens scale when comparing pituitary and adrenal origin in active patients and patients in remission. However, patients in remission who were on hydrocortisone replacement had a higher degree of WML than patients in remission who were not taking hydrocortisone $(P=0.023)$.

\section{Neuropsychological evaluation}

A third analysis was devoted to a neuropsychological evaluation (Table 3). Patients with active CS had worse neuropsychological performance in the memory domain

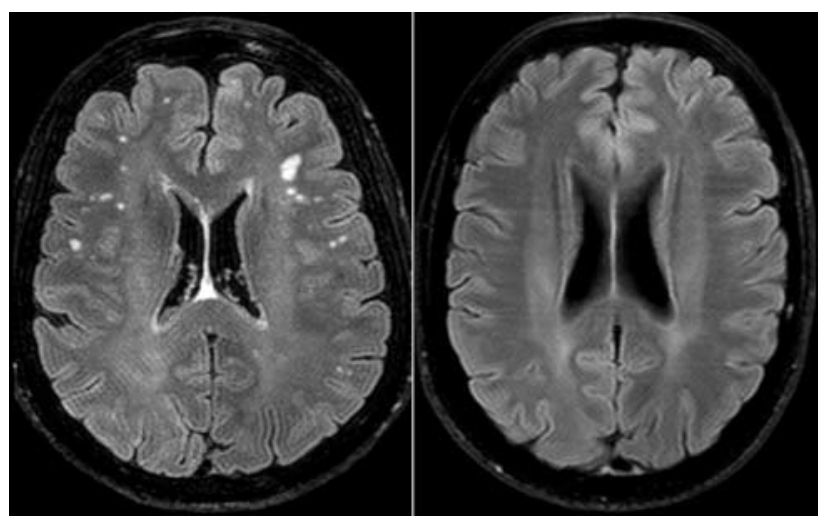

\section{Figure 1}

White matter lesions (the white spots seen across the MRI) in a patient with CS in remission (left) in comparison to her matched control (right). 
Table $3 Z$-scores of neuropsychological test results and normalized brain volumes of patients (CS active and in remission) and normal controls.

\begin{tabular}{|c|c|c|c|}
\hline & \multicolumn{2}{|c|}{ CS } & \multirow[b]{2}{*}{ Controls $(n=38)$} \\
\hline & Active $(n=15)$ & In remission $(n=23)$ & \\
\hline Memory (Z-scores) ${ }^{a}$ & $-0.49 \pm 0.46 *$ & $-0.05 \pm 0.76$ & $0.22 \pm 0.66$ \\
\hline Attention (Z-scores) ${ }^{\mathrm{b}}$ & $0.05 \pm 0.76$ & $0.01 \pm 0.55$ & $-0.03 \pm 0.83$ \\
\hline Executive function ( $Z$-scores $)^{c}$ & $-0.14 \pm 0.46$ & $0.03 \pm 0.39$ & $0.04 \pm 0.53$ \\
\hline $\begin{array}{l}\text { Information processing speed } \\
\text { (Z-scores })^{d}\end{array}$ & $-0.35 \pm 0.65$ & $-0.21 \pm 0.86$ & $0.15 \pm 0.72$ \\
\hline Motor functions (Z-scores) ${ }^{\mathrm{e}}$ & $-0.14 \pm 1.09$ & $-0.28 \pm 1.04$ & $0.22 \pm 0.75$ \\
\hline Depression (total score) ${ }^{f}$ & $9(3-19) *$ & $12(0-23) *$ & $2.5(0-16)$ \\
\hline \multicolumn{4}{|l|}{ Anxiety (total scores) ${ }^{9}$} \\
\hline State & $20.27 \pm 10.37 *$ & $20.27 \pm 11.15^{\star}$ & $11.36 \pm 7.56$ \\
\hline Trait & $24.93 \pm 9.86 *$ & $24.17 \pm 9.96 *$ & $13.58 \pm 7.97$ \\
\hline Brain white matter $\left(\mathrm{mm}^{3}\right)$ & $382267 \pm 64888$ & $386751 \pm 40564$ & $408458 \pm 31648$ \\
\hline Brain grey matter $\left(\mathrm{mm}^{3}\right)$ & $357470 \pm 33918^{*}$ & $365632 \pm 36581 *$ & $397766 \pm 34190$ \\
\hline Total brain volume $\left(\mathrm{mm}^{3}\right)$ & $739737 \pm 91350 *$ & $752383 \pm 73460 *$ & $806223 \pm 53847$ \\
\hline
\end{tabular}

*Significant differences between patients and controls $(P<0.05)$. All values are expressed as mean \pm s.D., except for depression, expressed as median and range.

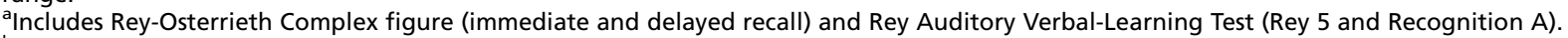

${ }^{b}$ Includes Digit Span Forward (total score) and Continuous Performance Test II (omissions).

'Includes Trail Making Test B (total time), FAS (total score), Animals (total score), Wisconsin Card Sorting Test (perseverative errors) and Digit Span Backwards (total score).

dIncludes Symbol Digit Modalities Test (total score), Wisconsin Card Sorting Test (mean time) and Continuous Performance Test II (Hit Reaction Time).

eIncludes Grooved Pegboard (total time for both dominant and non-dominant hand) and Trail Making Test A (total time).

${ }^{f}$ Beck Depression Inventory-II.

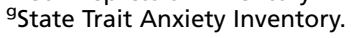

than controls $(P=0.002)$. No differences were found between patients in remission and controls. Both CS patient groups had more anxiety and depression than controls (in remission: STAI-State $P=0.017$, STAI-Trait $P<0.001$, BDI-II $P<0.001$; active CS: STAI-State $P=0.008$, STAI-Trait $P<0.001$, BDI-II $P<0.001$ ).

No differences were found in cognitive function when comparing patients of pituitary or adrenal origin (active or in remission). In patients in remission, no cognitive differences were found when comparing patients requiring hydrocortisone or not or who had undergone radiotherapy or not. Beck depression scores did not correlate with cognitive function in any of the patient groups.

\section{Brain volumes}

A final analysis was devoted to brain volumes (Table 3). Total brain volume and grey matter volume in both CS patient groups were reduced compared to controls (total volume: active CS $P=0.006$, in remission CS $P=0.012$; grey matter: active CS $P=0.001$, in remission CS $P=0.003)$. There were no differences in white matter volume between groups. No differences were found in brain volumes when comparing pituitary and adrenal origin in active patients and patients in remission.

\section{Correlations}

Neither the 10-year cardiovascular risk nor the vascular age correlated with the Scheltens scale score, although both negatively correlated with cognitive function and brain volume in patients in remission and controls (Table 4). Ten-year cardiovascular risk and vascular age did not correlate with anxiety or depression scores in any group.

The Scheltens scale did not correlate with total brain volume, grey matter, white matter, cognitive domains or depression and anxiety scores, either in the CS patient groups or in the control group (data not shown). WML severity positively correlated with diastolic blood pressure $(r=0.617, P=0.002)$ and hypertension duration $(r=0.543$, $P=0.007)$ in patients in remission. In active patients these clinical parameters did not correlate with the Scheltens scale. The Scheltens scale did not correlate with age, years of education, waist circumference, total cholesterol, glucose, triglycerides, urinary free cortisol, duration of hypercortisolism or delay to diagnosis in any group.

\section{Discussion}

Our study demonstrates that 10-year cardiovascular risk and vascular age (as described by the Framingham heart study (44)) are negatively associated with brain volume 
Table 4 Correlations of 10-year cardiovascular risk and vascular age with both brain volumes (white matter, grey matter and total brain volume) and cognitive function in CS patients and controls.

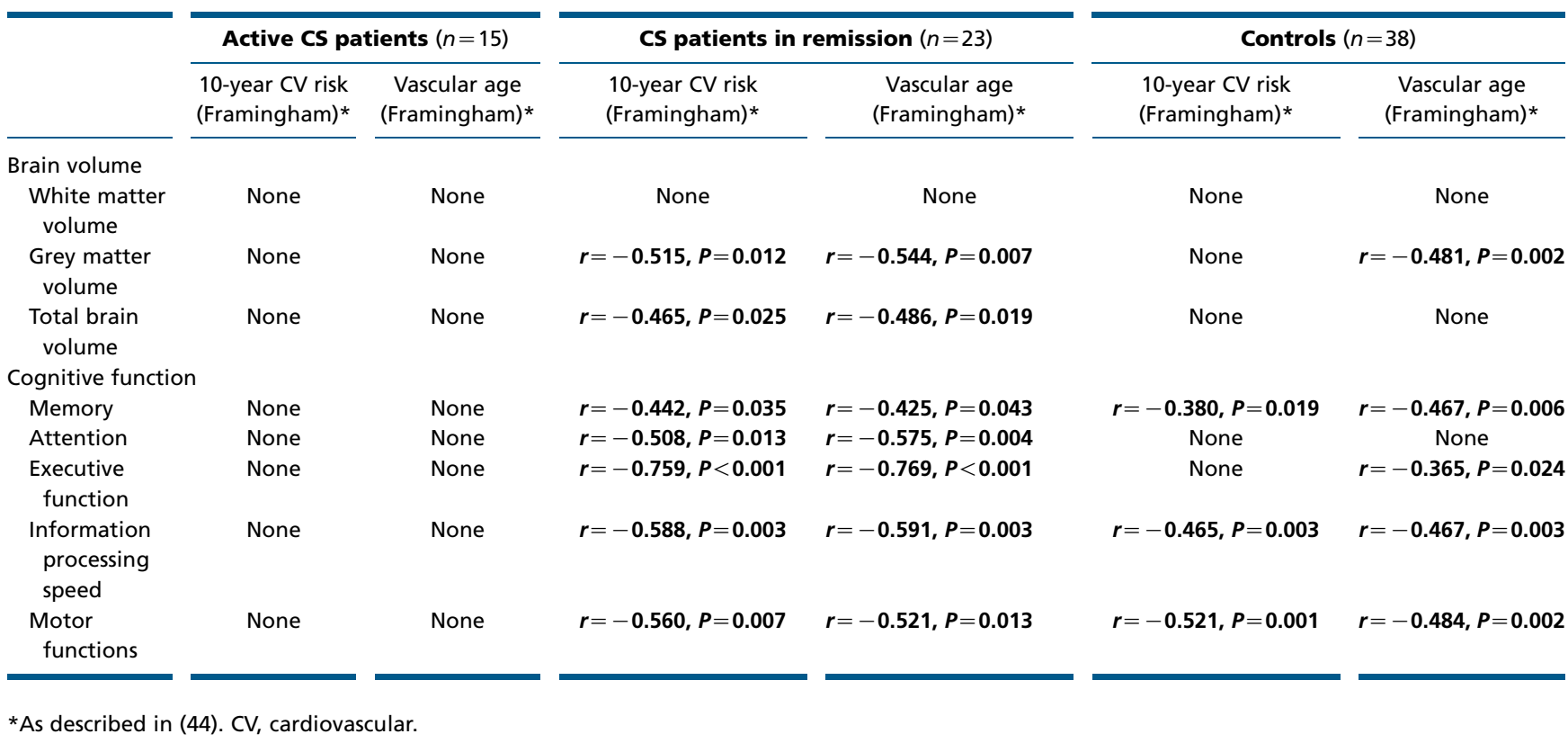

and cognitive function in patients in remission of CS. Patients in remission also have a higher degree of WML, measured with the Scheltens scale, than controls and patients with active CS. WML have been related to cardiovascular risk factors in the normal population (26), and our findings also show a relationship between WML and hypertension in patients in remission of CS.

Ten-year cardiovascular risk correlated with both brain volumes and cognitive function in patients in remission of CS. This is in line with previous findings in large samples of normal population $(45,46,47,48,49)$. Special attention should be paid to high 10-year cardiovascular risk, which may imply decreased cognitive function and reduced brain volumes. Current 10-year cardiovascular risk has also been associated with poorer future executive functions, in line with our results. This association has been found in middle aged but also in young populations (18-30 years), highlighting the importance of controlling cardiovascular risk even at earlier ages $(48,49)$.

The correlation between cardiovascular risk and both brain volume and cognitive function was not found in active patients with CS. This may be due to the small sample size of the active group, which may have prevented finding significant results. An analysis in a larger sample would be needed to confirm this hypothesis. Additionally, the effects of chronic hypercortisolism, still present in active patients, may affect brain volume and cognitive function more than cardiovascular risk. Hypercortisolism itself causes cognitive dysfunctions and reduces brain volume $(10,11,12,13,14,15,16,17)$. Possibly in the active population, hypercortisolism plays a more important role than cardiovascular risk on both cognitive function and brain volume. As active patients were affected by current hypercortisolism, it is possible that this situation (and the role of hypercortisolism on cognition and brain volume) may have prevented finding associations between cardiovascular risk and both cognitive function and brain volume.

We have not found any studies correlating vascular age and both brain volumes and cognitive function. The concept of 'vascular age' may be a useful tool in clinical practice for teaching patients, who may understand better that their vascular age is higher than their current age, rather than concepts like 10-year cardiovascular risk. In younger individuals, knowing their 'heart-age' has a high emotional impact, leading to changes in their lifestyle (50). Knowing that vascular age has been linked to poorer cognitive function and reduced brain volumes may also encourage patients to improve their healthy habits. In fact, Canadian guidelines for the diagnosis and treatment of dyslipidemia already recommend communicating vascular age to patients to improve hypertension and lipid control (51). 
The fact that WML were increased only in cured patients even if their vascular age was comparable to active patients may be surprising, although it is important to highlight that patients in remission had been exposed to cardiovascular risk for a longer time. In fact, the algorithm for 10-year cardiovascular risk and vascular age only includes current risk factors, not a measure of time exposed to cardiovascular risk. The correlations between WML and length of hypertension exposure are in line with this hypothesis.

According to some authors, the presence of WML has been reported in $11-21 \%$ of 64 -year-old patients. The presence of WML lesions increases with time, and the percentage of older patients with WML at the age of 82 increases to $94 \%$ (23). Taking into account the number of patients whose routine MRI reports described the presence of WML (in remission $73.9 \%$, mean age $44.3 \pm 9.3$; active $46.7 \%$, mean age $42.9 \pm 10.6$ ), it seems that the WML presence in our patient population is higher than expected, maybe in line with the brain-aging effect suggested by some authors in Cushing's syndrome (52).

Our results also showed a relationship between hypertension and WML in patients in remission. Hypertension is a known strong predictor for $\mathrm{WML}(53,54)$. More specifically, the severity of hypertension and bad control in treated hypertensive patients has been associated with the presence of WML $(55,56,57)$. These lesions may worsen over time. In uncontrolled hypertension, progression is higher in untreated rather than in treated patients, suggesting that hypertension treatment could reduce WML progression (58).

The duration of hypertension has also been associated with WML in the normal elderly population (57). In fact, apart from current hypertension, hypertension established 5 or 20 years before has also been associated to current WML in the old age $(57,59)$. This is in line with our results and could explain the differences in WML between active patients and patients in remission. The latter have longer hypertension exposure than active CS, and WML severity positively correlated with hypertension duration in patients in remission. These data indicate that the cause of WML may not be CS itself but rather longterm hypertension exposure caused by CS.

Regarding cognitive function, it is important to highlight that all $Z$-scores were within one s.D. both in active and treated CS, implying no severe impairments in cognition. These data are in line with previous literature in patients in remission in which all $Z$-scores were also within one s.D., even if significant differences in cognition between patients in remission and both normal controls and non-functioning adenomas were found (3). Regarding active patients, according to the literature, greater deficits may be expected $(16,60)$. Furthermore, significant differences with controls were only found for the memory domain. The fact that most of the active patients were on a cortisol-lowering medication may have prevented finding greater impairment. We had no data on cognitive performance before suffering CS; nevertheless, most of the patients complained about having a poor cognitive performance, mainly memory problems, in comparison to their prior capacities.

WML have been associated with reduced brain volumes and impaired cognitive function $(23,25,61)$, although this was not the case in our study. The Scheltens scale scores did not correlate with cognitive function or brain volume in patients with CS. Most of the literature studies on WML have been performed in older populations, where cognitive decline and brain atrophy are more pronounced. It is possible that the younger age of our patients may have prevented finding any significant correlations; however, a higher degree of WML may be related to poorer cognitive performance and reduced brain volumes when they reach an older age, which, given the cross-sectional nature of this study, could not be evaluated.

In fact, even if we did not find correlations between WML and cognitive function, WML are known to predispose to dementia, stroke and cognitive decline in old age $(23,25)$. This is a key finding with important clinical implications as it implies that this patient cohort may be cognitively compromised in the future. Nevertheless, control of hypertension may prevent progression of WML $(56,57)$ and reduce the risk of developing dementia and cognitive decline $(62,63)$. Thus, adequate control of hypertension would appear to be mandatory both in patients in remission, usually exposed to hypertension for a long time and with a higher degree of WML, and in active patients to prevent WML progression at an early stage. Patients should be informed on the risks of inadequate control of hypertension and on healthy habits to control hypertension. Education on drugs that may worsen hypertension such as non-steroidal anti-inflammatory drugs $(64,65)$ is worth recommending.

Patients in remission taking hydrocortisone had a higher degree of WML than patients who were not on hydrocortisone replacement. This would suggest limiting the use of hydrocortisone as much as possible; in practice, it may be difficult for patients to differentiate symptoms related to adrenal insufficiency from other causes. This 
may lead to taking extra doses of hydrocortisone, which may worsen hypertension (66). They should be encouraged to check their blood pressure regularly and to not 'routinely' take extra hydrocortisone doses when suffering from common complaints like tiredness or headache.

This study has several limitations. The small sample size is difficult to avoid in rare diseases, such as CS. It may have led to a low statistical power and possibly prevented the identification of significant findings, mainly in the active patients. Therefore, confirmatory analysis in larger samples of active patients would be needed, for instance, to check if there is a relationship between cardiovascular risk and both cognitive function and brain volume. Another limitation is the heterogeneity of the sample, because different causes of CS have been included, at different stages of the disease. Additionally, for nonparametric data in which differences were identified, no post hoc correction was performed. Longitudinal studies would be necessary to analyse WML progression in active patients and also to investigate the role of hypertension control in both active and in remission CS to prevent WML worsening.

In conclusion, our study describes negative correlations between cardiovascular risk and both brain volume and cognitive function in CS patients in remission. Moreover, it describes a high prevalence of WML in these patients, probably mediated by hypertension. These findings emphasize the importance of controlling cardiovascular risk factors to prevent brain damage in patients who have been diagnosed and treated for CS.

\section{Supplementary data}

This is linked to the online version of the paper at http://dx.doi.org/10.1530/ EJE-15-0600.

\section{Declaration of interest}

The authors declare that there is no conflict of interest that could be perceived as prejudicing the impartiality of the research reported.

\section{Funding}

This work was supported by the Instituto de Salud Carlos III, Spanish Ministry of Science and Innovation (MICINN, FIS080302), the European Commission (ERCUSYN PHP800200) and AGAUR (2014 SGR 355).

\section{Acknowledgements}

The authors thank all of the patients and controls that voluntarily participated in the study. We thank Dr Ignasi Gich for the critical review of the statistical analysis.

\section{References}

1 Arnaldi G, Angeli A, Atkinson AB, Bertagna X, Cavagnini F, Chrousos GP, Fava GA, Findling JW, Gaillard RC, Grossman AB et al. Diagnosis and complications of Cushing's syndrome: a Consensus Statement. Journal of Clinical Endocrinology and Metabolism $2003 \mathbf{8 8}$ 5593-5602. (doi:10.1210/jc.2003-030871)

2 Nieman LK, Biller BM, Findling JW, Newell-Price J, Savage MO, Stewart PM \& Montori VM. The diagnosis of Cushing's syndrome: an Endocrine Society Clinical Practice Guideline. Journal of Clinical Endocrinology and Metabolism 200893 1526-1540. (doi:10.1210/jc. 2008-0125)

3 Tiemensma J, Kokshoorn NE, Biermasz NR, Keijser BJ, Wassenaar MJ, Middelkoop HA, Pereira AM \& Romijn JA. Subtle cognitive impairments in patients with long-term cure of Cushing's disease. Journal of Clinical Endocrinology and Metabolism 201095 2699-2714. (doi:10.1210/jc. 2009-2032)

4 Tiemensma J, Biermasz NR, Middlekoop HA, van der Masr RC, Romijn JA \& Pereira AM. Increased prevalence of psychopathology and maladaptative personality traits after long-term cure of Cushing's disease. Journal of Clinical Endocrinology and Metabolism 201095 E129-E141. (doi:10.1210/jc.2010-0512)

5 van Aken MO, Pereira AM, Biermasz NR, van Thiel SW, Hoftijzer HC, Smit JW, Roelfsema F, Lamberts SW \& Romijn JA. Quality of life in patients after long-term biochemical cure of Cushing's disease. Journal of Clinical Endocrinology and Metabolism 200590 3279-3286. (doi:10.1210/jc.2004-1375)

6 Lindsay JR, Nansel T, Baid S, Gumowski J \& Nieman LK. Long-term impaired quality of life in Cushing's syndrome despite initial improvement after surgical remission. Journal of Clinical Endocrinology and Metabolism 200591 447-453. (doi:10.1210/jc.2005-1058)

7 Arnaldi G \& Boscaro M. New treatment guidelines on Cushing's disease. F1000 Medicine Reports 20091 64. (doi:10.3410/M1-64)

8 Biller BM, Grossman AB, Stewart PM, Melmed S, Bertagna X, Bertherat J, Buchfelder M, Colao A, Hermus AR, Hofland LJ et al. Treatment of adrenocorticotropin-dependent Cushing's syndrome: a consensus statement. Journal of Clinical Endocrinology and Metabolism 200893 2454-2462. (doi:10.1210/jc.2007-2734)

9 Joëls M, Karst H, Krugers HJ \& Lucassen PJ. Chronic stress: implications for neuronal morphology, function and neurogenesis. Frontiers in Neuroendocrinology 200728 72-96. (doi:10.1016/j.yfrne.2007.04.001)

10 Forget H, Lacroix A, Somma M \& Cohen H. Cognitive decline in patients with Cushing's syndrome. Journal of the International Neuropsychological Society 20006 20-29. (doi:10.1017/S13556177 00611037)

11 Santos A, Resmini E, Crespo I, Pires P, Vives-Gilabert Y, Granell E, Valassi E, Gómez-Ansón B, Martínez Momblán MA, Mataró M et al. Small cerebellar cortex volume in patients with active Cushing's syndrome. European Journal of Endocrinology 2014171 461-469. (doi:10.1530/EJE-14-0371)

12 Bourdeau I, Bard C, Forget H, Boulanger Y, Cohen H \& Lacroix A. Cognitive function and cerebral assessment in patients who have Cushing's syndrome. Endocrinology and Metabolism Clinics of North America 200534 357-369. (doi:10.1016/j.ecl.2005.01.016)

13 Starkman MN, Gebarski SS, Berent S \& Schteingart DE. Hippocampal formation volume, memory dysfunction, and cortisol levels in patients with Cushing's syndrome. Biological Psychiatry 199232 756-765. (doi:10.1016/0006-3223(92)90079-F)

14 Resmini E, Santos A, Gómez-Anson B, Vives Y, Pires P, Crespo I, Portella MJ, de Juan-Delago M, Barahona MJ \& Webb SM. Verbal and visual memory performance and hippocampal volumes, measured by 3-Tesla magnetic resonance imaging, in patients with Cushing's syndrome. Journal of Clinical Endocrinology 201297 663-671. (doi:10.1210/jc.2011-2231) 
15 Andela CD, van Haalen FM, Ragnarsson O, Papakokkinou E, Johannson G, Santos A, Webb SM, Biermasz NR, van der Wee NJ, Pereira AM et al. Mechanisms in Endocrinology: Cushing's syndrome causes irreversible effects on the human brain: a systematic review of structural and functional magnetic studies. European Journal of Endocrinology 2015173 R1-R14. (doi:10.1530/EJE-14-1101)

16 Mauri M, Sinforiani E, Bono G, Vignati F, Berselli ME, Attanasio R \& Nappi G. Memory impairment in Cushing's disease. Acta Neurologica Scandinavica 199387 52-55. (doi:10.1111/j.1600-0404. 1993.tb04075.x)

17 Crespo I, Granell-Moreno E, Santos A, Valassi E, De Juan-Delago M, Vives-Gilabert Y, Webb SM, Gómez-Ansón B \& Resmini E. Impaired decision-making process and thinner prefrontal cortex in patients with Cushing's syndrome. Clinical Endocrinology 201481 826-833. (doi:10. 1111/cen.12564)

18 Ragnarsson O, Berglund P, Eder DN \& Johannsson G. Long-Term cognitive impairments and attentional deficits in patients with Cushing's disease and cortisol-producing adrenal adenoma in remission. Journal of Clinical Endocrinology and Metabolism 201297 1640-1648. (doi:10.1210/jc.2012-1945)

19 Andela CD, van der Werff SJ, Pannekoek JN, van den Berg SM, Meijer OC, van Buchem MA, Rombousts SA, van der Mast RC, Romijn JA, Tiemensma J et al. Smaller grey matter volumes in the anterior cingulate cortex and greater cerebellar volumes in patients with long-term remission of Cushing's disease: a case-control study. European Journal of Endocrinology 2013169 811-819. (doi:10.1530/ EJE-13-0471)

20 Colao A, Pivonello R, Spiezia S, Faggiano A, Ferone D, Filippella M, Marzullo P, Cerbone G, Siciliani M \& Lombardi G. Persistence of increased cardiovascular risk in patients with Cushing's disease after five years of successful cure. Journal of Clinical Endocrinology and Metabolism 199984 2664-2672. (doi:10.1210/jcem.84.8.5896)

21 Barahona MJ, Sucunza N, Resmini E, Fernández-Real JM, Ricart W, Moreno-Navarrete JM, Puig T, Farrerons J \& Webb SM. Persistent body fat mass and inflammatory marker increases after long-term cure of Cushing's syndrome. Journal of Clinical Endocrinology and Metabolism 200994 3365-3371. (doi:10.1210/jc.2009-0766)

22 Gorelick PB, Scuteri A, Black SE, Decarli C, Greenberg SM, Iadecola C, Launer LJ, Laurent S, Lopez OL, Nyenhuis D et al. Vascular contributions to cognitive impairment and dementia: a statement for healthcare professionals from the American Heart Association/ American Stroke Association. Stroke 201142 2672-2713. (doi:10.1161/ STR.0b013e3182299496)

23 Debette S \& Markus HS. The clinical importance of white matter hyperintesities on brain magnetic resonance imaging: systematic review and meta-analysis. British Medical Journal 2010331 c3666. (doi:10.1136/bmj.c3666)

24 Black S, Gao F \& Bilbao J. Understanding white matter disease: imagingpathological correlations in vascular cognitive impairment. Stroke 2009 40 S48-S52. (doi:10.1161/STROKEAHA.108.537704)

25 Mataró M, Soriano-Raya JJ, López-Oróliz J, Miralbell J \& DacostaAguayo R. Cerebrovascular markers in lowered cognitive function. British Medical Journal 201442 (Suppl 4) S383-S391.

26 Verdelho A, Madureira S, Ferro JM, Basile AM, Chabriat H, Erkinjuntti T, Fazekas F, Hennerici M, O'Brien J, Pantoni L et al. LADIS study differential impact of cerebral white matter changes, diabetes, hypertension and stroke on cognitive performance among nondisabled elderly. The LADIS study. Journal of Neurology, Neurosurgery, and Psychiatry 200778 1325-1330. (doi:10.1136/jnnp.2006.110361)

27 Xiong YY \& Mok V. Age-related white matter changes. Journal of Aging Research 20112011 617927. (doi:10.4061/2011/617927)

28 van der Werff SJ, Andela CD, Nienke Pannekoek J, Meijer OC, van Buchem MA, Rombouts SA, van der Mast RC, Biermasz NR, Pereira AM $\&$ van der Wee AJ. Widespread reductions of white matter integrity in patients with long-term remission of Cushing's disease. NeuroImage. Clinical 20144 659-667. (doi:10.1016/j.nicl.2014.01.017)
29 Pires P, Santos A, Vives-Gilabert Y, Webb SM, Sainz-Ruiz A, Resmini E, Crespo I, de Juan-Delago M \& Gómez-Anson B. White matter alterations in the brain of patients with active, remitted and cured Cushing's syndrome: A DTI study. AJNR. American Journal of Neuroradiology 201536 1043-1048. (doi:10.3174/ajnr.A4322)

30 Oldfield RC. The assessment and analysis of handedness: the Edinburgh inventory. Neuropsychologia 19719 97-113. (doi:10.1016/00283932(71)90067-4)

31 Rey A. L'examin Clinique en Psychologie. Paris: Presses Universitaires de France, 1958.

32 Rey A. L'examen psychologique dans les cas d'encephalopathie traumatique. Archives de Psychologie 194128 286-340.

33 Wechsler D. WAIS-III, Wechsler Adult Intelligence Scale-Third Edition. Administration and Scoring Manual. San Antonio, TX, USA: The Psychological Corporation, 2001.

34 Conner's CK. Conner's Continuous Performance Test II, Version 5 for Windows (CPT II): Technical Guide and Software Manual. North Tonawanda, NY: Multi-Health Systems, 2008.

35 Reitan R. Trail making test: Manual for administration, scoring, and interpretation. Bloomington: Indiana University, 1956.

36 Benton AL, Hamsher Kd. Multilingual Aphasia Examination. Iowa City: University of Iowa, 1976.

37 Goodglass H, Kaplan E, Barresi B. Boston diagnostic aphasia examination set, 3/E. Philadelphia: Lippincott Williams \& Wilkins, 2001.

38 Kongs SK, Thompson LL, Iverson GL, Heaton RK. Wisconsin Card Sorting Test-64 Card Version. Professional Manual. Lutz, FL: Psychological Assessment Resources, 2000.

39 Smith A. Symbol Digit Modalities Test. Los Angeles, California: Western Psychological Services, 1973.

40 Lafayette Instrument Company. Grooved Pegboard: Model 32025; User's Manual. Lafayette: Lafayette Instrument Company, 2003.

41 Lezak MD, Howieson DB, Bigler ED, Tranel D. Neuropsychological assessment. 5th edn, New York: Oxford University Press, 2012.

42 Strauss E, Sherman EM, Spreen O. A compendium of neuropsychological tests, administration, norms and commentary. 3rd edn. NewYork: Oxford University Press, 2006.

43 Scheltens P, Barkhof F, Leys D, Pruvo JP, Naura JJ, Vermersch P, Steinling $M \&$ Valk J. A semiquantitative rating scale for the assessment of signal hyperintensities on magnetic resonance imaging. Journal of the Neurological Sciences 1993114 7-12. (doi:10.1016/0022510X(93)90041-V)

44 D'Agostino RB, Vasan RS, Pencina MJ, Wolf PA, Cobain M, Massaro JM $\&$ Kannel WB. General cardiovascular risk profile for use in primary care: the Framingham Heart Study. Circulation 2008117 743-753. (doi:10.1161/CIRCULATIONAHA.107.699579)

45 Knopman DS, Mosley TH, Catellier DJ, Sharrett AR \& Atherosclerosis Risk in Communities (ARIC) Study. Cardiovascular risk factors and cerebral atrophy in a middle-aged cohort. Neurology 200565 876-881. (doi:10.1212/01.wnl.0000176074.09733.a8)

46 Longstreth WT, Arnold AM, Manolio TA, Burke GL, Bryan N, Jungreis CA, O'Leary D, Enright PL \& Fried L. Clinical correlates of ventricular and sulcal size on cranial magnetic resonance imaging of 3,301 elderly people. The Cardiovascular Health Study. Collaborative Research Group. Neuroepidemiology 200019 30-42. (doi:10.1159/ 000026235)

47 Seshadri S, Wolf PA, Beiser A, Elias MF, Au R, Kase CS, D'Agostino RB \& DeCarli C. Stroke risk profile, brain volume, and cognitive function: the Framingham Offspring Study. Neurology 200463 1591-1599. (doi:10. 1212/01.WNL.0000142968.22691.70)

48 Nishtala A, Preis SR, Beiser A, Devine S, Hankee L, Seshadri S, Wolf PA \& Au R. Midlife cardiovascular risk impacts executive function: Framingham offspring study. Alzheimer Disease and Associated Disorders 201428 16-22. (doi:10.1097/WAD.0b013e3182a715bc)

49 Yaffe K, Vittinghoff E, Pletcher MJ, Hoang TD, Launer LJ, Whitmer R, Coker LH \& Sidney S. Early adult to midlife cardiovascular risk factors 
and cognitive function. Circulation 2014129 1560-1567. (doi:10.1161/ CIRCULATIONAHA.113.004798)

50 Soureti A, Hurling R, Murray P, van Mechelen W \& Cobain M. Evaluation of a cardiovascular disease risk assessment tool for the promotion of healthier lifestyles. European Journal of Cardiovascular Prevention and Rehabilitation 201017 519-523. (doi:10.1097/HJR. Ob013e328337ccd3)

51 Anderson TJ, Grégoire J, Hegele RA, Couture P, Mancini GB, McPherson R, Francis GA, Poirier P, Lau DC, Grover S et al. 2012 Update of the Canadian Cardiovascular Society guidelines for the diagnosis and treatment of dyslipidemia for the prevention of cardiovascular disease in the adult. Canadian Journal of Cardiology 2013 29 151-167. (doi:10.1016/j.cjca.2012.11.032)

52 Michaud K, Forget H \& Cohen H. Chronic glucocorticoid hypersecretion in Cushing's syndrome exacerbates cognitive aging. Brain and Cognition 200971 1-8. (doi:10.1016/j.bandc.2009.02.013)

53 Longstreth WT Jr, Manolio TA, Arnold A, Burke GL, Bryan N, Jungreis CA, Enright PL, O'Leary D \& Fried L. Clinical correlates of white matter findings on cranial magnetic imaging of 3301 elderly people: The Cardiovascular Health Study. Stroke 199627 1274-1282. (doi:10.1161/01.STR.27.8.1274)

54 Basile AM, Pantoni L, Pracucci G, Asplund K, Chabriat H, Erkinjuntti T, Fazekas F, Ferro JM, Hennerici M, O'Brien J et al. Age, hypertension and lacunar stroke are the major determinants of the severity of age-related white matter changes. The LADIS (Leukoaraiosis and Disability in the Elderly) Study. Cerebrovascular Diseases 200621 315-322. (doi:10.1159/ 000091536)

55 Shimada K, Kawamoto A, Matsubayashi K \& Ozawa T. Silent cerebrovascular disease in the elderly. Correlation with ambulatory pressure. Hypertension 199016 692-699. (doi:10.1161/01. HYP.16.6.692)

56 Liao D, Cooper L, Cai J, Toole JF, Bryan N, Hutchinson RG \& Tyroler HA. Presence and severity of cerebral white matter lesions and hypertension, its treatment and its control. The ARIC Study. Stroke 1996 27 2262-2270. (doi:10.1161/01.STR.27.12.2262)

57 De Leeuw FE, de Groot JC, Oudkerk M, Witteman JC, Hofman A, van Gijn J \& Breteler MM. Hypertension and cerebral white matter lesions in a prospective cohort study. Brain 2002125 765-772. (doi:10.1093/ brain/125.4.765)

58 Verhaaren BF, Vernooij MW, de Boer R, Hofman A, Niessen WJ, van der Lugt A \& Ikram MA. High blood pressure and cerebral white matter lesion progression in the general population. Hypertension $2013 \mathbf{6 1}$ 1354-1359. (doi:10.1161/HYPERTENSIONAHA.111.00430)

59 Debette S, Seshadri S, Beiser A, Au R, Himali JJ, Palumbo C, Wolf PA \& DeCarli C. Midlife vascular risk factor exposure accelerates structural brain aging and cognitive decline. Neurology 201177 461-468. (doi:10.1212/WNL.0b013e318227b227)

60 Whelan TB, Schteingart DE, Starkman MN \& Smith A. Neuropsychological deficits in Cushing's syndrome. Journal of Nervous and Mental Disease 1980168 753-757. (doi:10.1097/00005053198012000-00008)

61 Appelman AP, Exalto LG, van der Graaf Y, Biessels GJ, Mali WP \& Geerlings MI. White matter lesions and brain atrophy: more than shared risk factors? A systemiatic review Cerebrovascular Diseases 2009 28 227-242. (doi:10.1159/000226774)

62 Forette F, Seux ML, Staessen JA, Thijs L, Birkenhäger WH, Babarskiene MR, Babeanu S, Bossini A, Gil-Extremera B, Girerd X et al. Prevention of dementia in randomised double-blind placebo-controlled Systolic Hypertension in Europe (Syst-Eur) trial. Lancet 1998352 1347-1351. (doi:10.1016/S0140-6736(98)03086-4)

63 Levi Marpillat N, Macquin-Mavier I, Tropeano AI, Bachoud-Levi AC \& Maison P. Antihypertensive classes, cognitive decline and incidence of dementia: a network meta-analysis. Journal of Hypertension $2013 \mathbf{3 1}$ 1073-1082. (doi:10.1097/HJH.0b013e3283603f53)

64 Johnson AG. NSAIDs and increased blood pressure. What is the clinical significance? Drug Safety 199717 277-289. (doi:10.2165/00002018199717050-00001)

65 Kalafutova S, Juraskova B \& Vlcek J. The impact of combinations of non-steroidal anti-inflammatory drugs and anti-hypertensive agents on blood pressure. Advances in Clinical and Experimental Medicine 2014 23 993-1000. (doi:10.17219/acem/37357)

66 Sudhir K, Jennings GL, Esler MD, Korner PI, Blombery PA, Lambert GW, Scoggins B \& Whitworth JA. Hydrocortisone-induced hypertension in humans: pressor responsiveness and sympathetic function. Hypertension 198913 416-421. (doi:10.1161/01.HYP.13.5.416)

Received 17 June 2015

Revised version received 29 August 2015

Accepted 4 September 2015 